\title{
Evaluation of agricultural ecological environment in determining the capable areas: A case study of city of Esfahan, Iran
}

\author{
Sedigheh Kiani Salmi ${ }^{a^{*}}$, Sayed Eskandar Seydaie ${ }^{\mathrm{b}}$, Sayed Hedayat-o-lah Noori ${ }^{\mathrm{c}}$ and Dariush Rahimic
}

${ }^{a} P h D$ student in Geography, University of Isfahan, Iran

${ }^{b}$ Associate Professor of Geography Department, University of Isfahan, Iran

${ }^{c}$ Assistant Professor of Geography Department, University of Isfahan, Iran

C H R O N I C L E

Article history:

Received July 28, 2012

Received in revised format

19 November 2012

Accepted 20 November 2012

Available online

November 262012

Keywords:

Evaluation

Land use

Application of agriculture

The east area of Esfahan

\section{A B S T R A C T}

The nature of different activities in production, agriculture as well as distribution and consumption section, called as expansionist activities, largely influence the ability of the land. Production of consumable material, which is required for increasing population in various areas, and their attractions make it possible to earn more profit and it causes a significant pressure on soil and water resources and can threaten environmental pollution and human food security. A self-interested attitude on land resources has led to run short-term programs without considering the ecological capability of the land. These mentioned problems are, significantly intensified particularly in arid and semi-arid areas with severe limitations of water and soil quality and quantity. Therefore, land allocation based on ecological capability and selfpurification indexes, used for land use planning, is an appropriate response to meet the deficiencies noted. This paper studies the agricultural capable lands based on land capability. The proposed study uses GIS software capabilities with application of the environmental ability evaluation model, as a holistic approach, to make sustainable development research in the region. The results indicate that suitable lands for agriculture in the whole area in different classes are widespread and with regards to dependency of more than 90 percent of people to agricultural activities, serious attention of authorities is required for providing the appropriate baseline and avoiding land use change to develop this activity.

\section{Introduction}

These days, knowledge underpins all foundations of daily lifestyle. Human activities as an essential element of international competitions influence on human health, quality of daily life, the most important motivating force of global change and knowledge can significantly contribute to all these issues (Smith \& Kelly, 2003). Use of resources and environmental data as one of the major factors in the development of diverse geographical areas also depends on a comprehensive understanding and having a thorough knowledge of the facilities, opportunities, capabilities and limitations (Scottish 
Environment LINK, 2009). Development and maintenance of ecological processes are achievable as long as land is used proportion to its capabilities and competencies. Therefore, before running various activities, identification of land features and capabilities are very important. Otherwise, the use of the land capabilities would be in a way that natural and ecological constraints prevent them from continuing the activities. Therefore, it is important to focus on the perspective of various talents and in this field, a wrong application of land could cause a danger for an area and may even cause problems for other types of land use (Carsjens \& van der Knaap, 2002).

According to Carsjens and van der Knaap (2002), in the Netherlands, there is an ongoing debate on how to allocate the available space among various kinds of land use, the rural area is under continuous pressure from urban development and multi-purpose land implementation plays essential role on ecological development. Land-use allocation issues can be classified as complex planning problems, with a large number of stakeholders involved. Obviously, the decisions made with respect to land use need to be crystal clear to these stakeholders. Different techniques have been developed to support land allocation issues. Nevertheless, the analysis of topological relationships, initiated by socio-economic and biophysical processes, and the spatial configuration of various land uses have been often neglected, more specifically for agricultural planning. Neglecting the spatial configuration and these relationships yield in spatial fragmentation of land use, thus endangering continuous land use. Quaye et al. (2010) performed biophysical analysis to determine the potentials of the extensive system and its future sustainability. According to this survey, food production in Ghana had increased steadily over the past two decades and correlated highly with cropped area and population. Sufficient food production could be sustained in the short term. However, in the longer term, the food situation in Ghana seem precarious if population growth continues while land remains the same. Gulinck et al. (2001) presented a method to the demarcation and analysis of an expanded zone near a new reservoir near Bulawayo, bigger than an originally designated narrow natural fringe.

This paper focuses on a method to address land-use allocation issues where the topological relationships are taken into account. The method is implemented in a Geographical Information System (GIS). Two cases for Dutch agriculture are discussed.

The first step is scientific identification of available resources in each area in order to identify the activities, which are commensurate with the potential for environmental action, and Geographic Information System allows using of geographic information to help policy makers and decision makers solve any problems. Various methods can be used for land use planning and they usually have been adopted from technical sciences, natural sciences and social sciences (FAO, 1993). Although the physical and biological sciences have had important impacts on decisions about land use, but applications are determined by human behavior.

An increase on population, consumerism and strong tendency toward greater welfare are the most important characteristics of urban communities and different areas of the world. Meeting the needs that community expects, in the first step, is based on the use of non-renewable resources and excessive ecologically pressure on land resources. These results lead to excessive loss of natural resources, pollution of water, soil, air, and inadequate distribution of resources. Industrial development and economic growth, as well as population growth, are factors that have caused different crisis (Miller, 1994; Dasman, 1984).

Due to the nature of agricultural activities in the section of production, distribution and consumption, it is an expansive work, which would largely influence the capabilities of the land. Consumables products for growing populations in different areas and the attraction of these needs to earn more profit have caused significant pressure on the resources of soil and water. Therefore, human society has been threatened by environmental pollution and food security. A self-interested attitude on land resources has led to short-term programs without considering the ecological capability of the land; the mentioned problems are exacerbated significantly, especially in arid and semi-arid areas, which are 
facing with severe limitations of soil and water quality and quantity. So, land allocation based on ecological potential and self-purification measures, which can be used in the framework of the land use planning, is a proper response to resolve the deficiencies listed. In this context, geographical studies on area and understanding of natural and human potential in every area, help planners identify the area development strategies based on the environmental potentials, identify the area development strategies and offer a proper tailored program to area conditions. A fundamental basis for adequate production of vegetation products is provided by use agricultural along with sustainable management of land (The World Bank, Washington, 2006). Since the majority of household, especially in developing societies depend on land and other natural resources to meet their vital needs and agriculture in most countries like Iran and the studied area is the main activity, conducting such researches are considered as a step towards achieving sustainable development. The purpose of this study is to consider the area's strengths and weaknesses and determine the ecological capability of land in the agricultural sector, and it has a lot of importance; because the population over 150.000 people directly and indirectly are dependent on agriculture in the area

\section{Research Experience}

All countries are forced to study the management of land including maintenance of the land, valuation and determination of its use (Scottish Environment LINK, 2009). Studies, which focus on the environment and the environmental potential can be attributed to the late decades of the 20th century and Iran is not excluded from this; examples of these studies are discussed in the following.

According to Makhdoom (1991), determining the ecological capacity of Iran's north land is effective to coordinate different sectors of development. Noori (1994) believes that determining the agricultural potential is a proper strategy for economic balance in Iran's Central areas. Herbert et al. (2000) implemented land use planning development model in Zimbabwe and integrated local livelihoods and ecotourism to reduce the negative effects of economic, social and environmental factors. Quaye et al. (2010) considered evaluation of natural resources and land potential in Ghana to create food security as a fundamental issue. Sanetlman et al (2004) used statistical techniques and GIS to study agricultural status quo and future of the Ohio state in America and identified capable areas. Galnyk (2000) considered a major role for land use and resource land use planning. The proposed study of this paper is associated with city of Esfahan, Iran. Fig. 1 shows characteristics of the city.

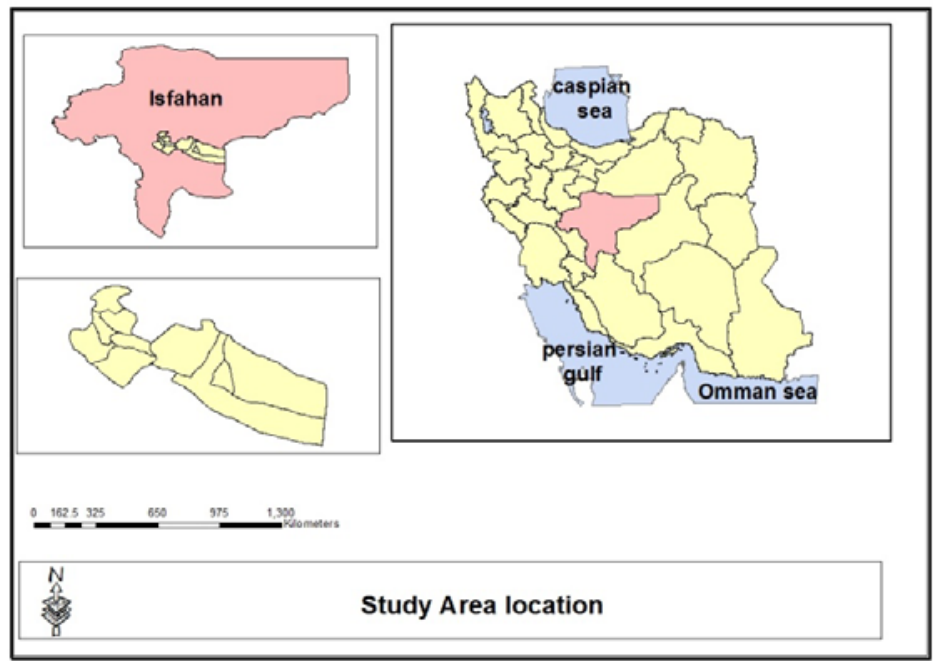

Fig. 1. Characteristics of city of Esfahan 


\section{Research Method}

In this descriptive-analytical research, at first step, ecological zone has been identified, then by using the GIS software, available maps and aerial and satellite photographs, the maps of ecological resources, altitude classes, slope, slope aspect, land and other related information are plotted, and then, the capable agricultural areas have been evaluated and determined by combination and evaluation of maps. Evaluation of ecological potential means the determination of the land potential or natural use (Tavakol, 1997). Since the land use planning is a complex concept, multidimensional and often highly political process to obtain the stability, the multi-faceted dimensions of economic, environmental and social must be considered (Alberta Urban Municipalities Association, 2007). Ecological environment evaluation process consists of three major parts:

\subsection{Identification of ecological resources}

The identification process includes the following steps:

\subsubsection{Preparing maps slope}

First, it is essential to determine swing classes in order to prepare the maps slope. According to the researches, the most common classes are described in Table 1 and Fig. 2.

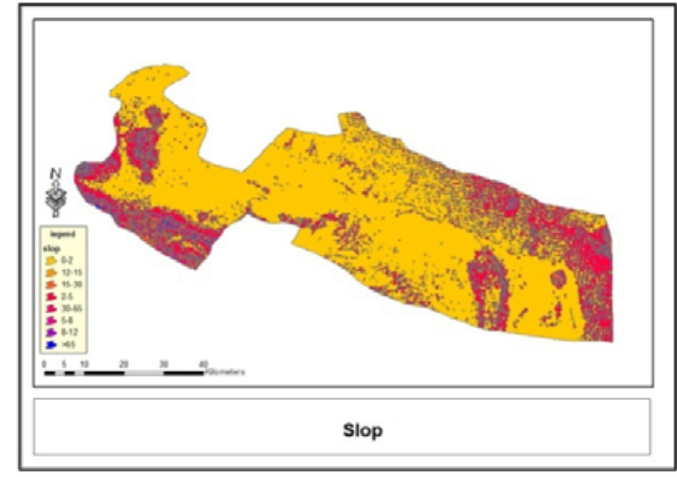

Fig. 2. Characteristics of slop

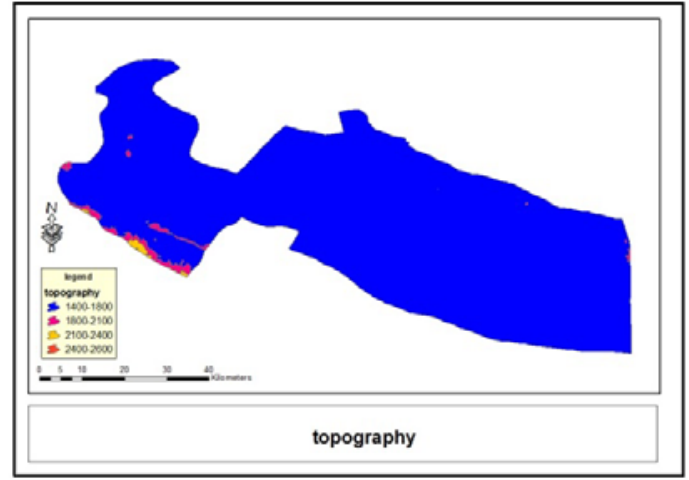

Fig. 3. Topography of region

Slope classes map using the following formula can be obtained from topographic maps.

$w=(\Delta H \times 100) /(M \times P)$,

where $w$ is distance between the contour lines, $\Delta H$ is the vertical distance between the contour lines, $M$ is map scale and $P$ is considered percentage of slope. Note that the slope less than 10 percent cannot be a cause for considerable latitude. Thus, it is considered undirected.

\section{Table 1}

Slope classes, altitude, aspect and soil

\begin{tabular}{cllll}
\hline Class & Percent Slope & Altitude & Geographical aspect & Soil \\
\hline Class 1 & $0-2$ & Less than 1000 m & P5 & Shallow sandy soil \\
Class 2 & $2-5$ & $1000-1200$ & North & Shallow loamy sandy soil \\
Class 3 & $5-8$ & $1200-1400$ & North east & Semi- deep loamy sandy soil \\
Class 4 & $8-12$ & $1400-1800$ & East & Deep sandy soil \\
Class 5 & $12-15$ & $1800-2100$ & South east & sandy clay loam soil Semi-deep \\
Class 6 & $15-30$ & $2100-2400$ & South & Clay loam soil semi-deep \\
Class 7 & $30-65$ & $2400-260$ & South West & Deep loamy clay soil \\
Class 8 & More than 65 & More than 2600 & west & Clay loam soil semi-deep \\
Class 9 & & North West & Deep loamy clay soil \\
\multicolumn{2}{c}{ Class 10 } & & & Sandy clay loam soil semi-deep \\
\hline Source: (Makhdoom, 2006) (National Center of Land, 2005)
\end{tabular}




\subsubsection{Plot the map of sea altitude}

To plot the map of sea altitude, topographic maps is used such as slope maps. Therefore, the altitude of the classification in Table 1 is used for the studied areas (Fig. 3).

\subsubsection{Plot the geographical aspects map}

For plotting the geographic aspects map by using topographic map, which depends on the situation, up to 9 aspect class is considered (See Table 1 and Fig. 4).

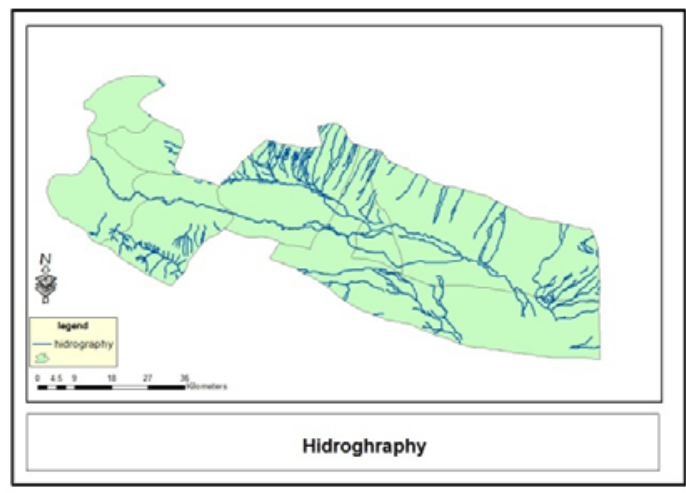

Fig. 4. Hidroghraphy

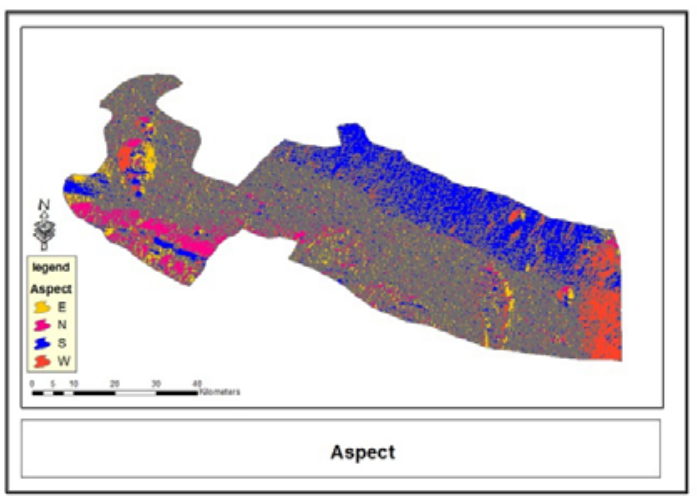

Fig. 5. Aspect

\subsubsection{Plot the unit maps of land' shape}

The shape of land consists of land neutral units where each unit has become the current shape under the same conditions of climate, weathering, erosion, etc. The land shape map is plotted by putting on each other the map of slope classes and map of height classes and geographical aspect. The act of over laying maps on each other is performed by two-combined and multi-combined methods. The method used in this study has two combinations, because it gives more accurate and better results. For this purpose, according to the following formula, the maps are overlaid on each other, respectively, by using Eq. (2) as follows,

$E 1=J 2(I 3-1)+J 4$

where $E 1$ is code or combined unit number, $J 2$ is total number of map classes which lay below, $I 3$ is the class number of upper map and $I 4$ is the class number of map, which lay on.

\subsubsection{Plot the hydrographic maps (See Fig. 5)}

\subsubsection{Plot the soil map (See Fig. 6)}

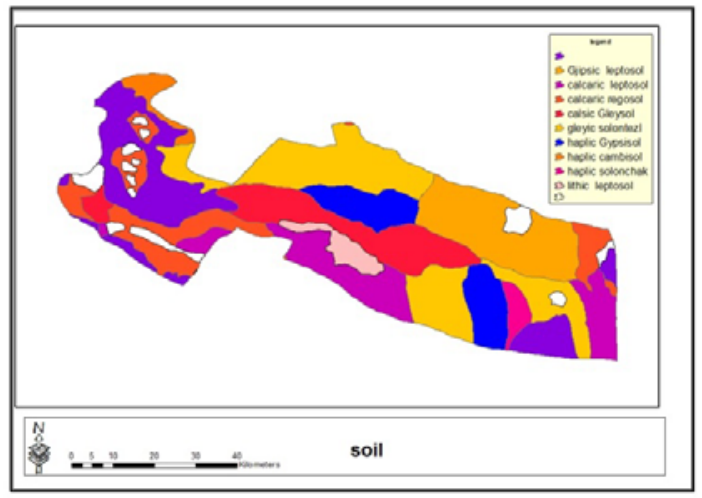

Fig. 6. Characteristics of soil 3.1.7 Plot the map of plant community (See Fig. 7)

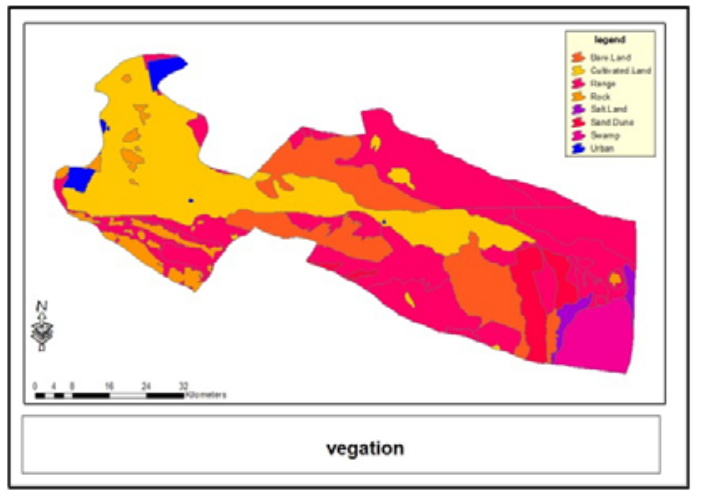

Fig. 7. Characteristics of vegation 


\subsection{Analyzing and Summarizing the Sources}

Analyzing and summarizing sources are considered as combining all the classes of ecological resources together, to obtain homogeneous land units classes of ecological resources. The process is as follows:

\subsubsection{Put the unit maps topographical on the soil type map and plot the environmental unit maps grade 1}

3.2.2 Put the map grade 1 on the community map or vegetation type and plot the environmental units grad 2

3.2.3 Put the map grade 2 on the vegetation density map and plot the final environmental units (Fig. 8)

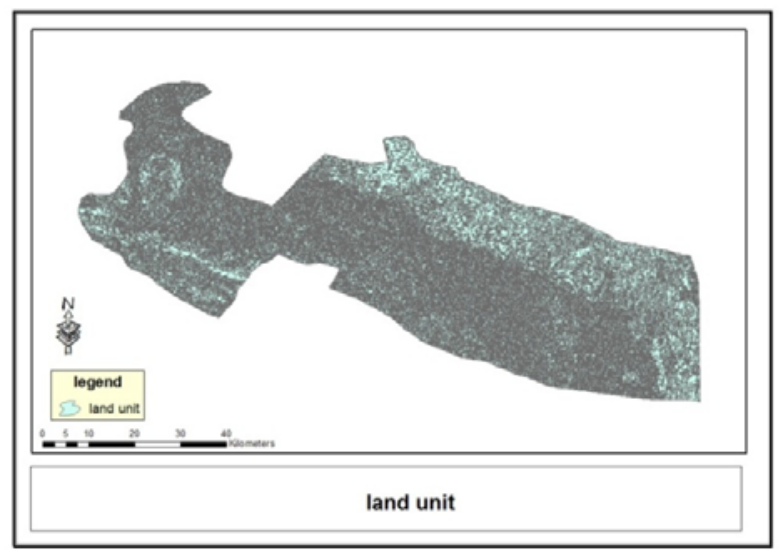

Fig. 8. Characteristics of land unit

\subsubsection{Plot the environmental units attributes table (Characteristics of ecologically sustainable)}

\subsection{Evaluation of ecological environment}

Ecological evaluation of land for agricultural and use is the middle stage of the land use planning. In this phase the collected data in the phase of analysis and summarizing in the environmental unit with the ecological model built for agricultural land use, the most suitable locations are selected (Noroozi Avargani 2003). Based on studies conducted in Iran and countries that are ecologically similar to Iran, Iran's ecological model has presented for agricultural use, which is an alphabetical model (Makhdoom, 2006) and Table 2 shows this model.

\section{Case study}

The studied area location in Esfahan is located between east longitudes 5303'40" to 56037'16" and to north latitude 3209'23" (Isfahan tourism master plan, 2009). The area has a rural population of 135,447, which is distributed in 34,786 households; more than 95 percent of these households are directly or indirectly dependent on agriculture (Agriculture Organization of Isfahan city). However, in recent years, due to certain administrative problems of water resources, the area has encountered some difficulties. If there were no improvement in water resources management, agriculture would be destroyed in the area. Fig. 1 indicates the location of the studied area.

\section{Results}

As described in the section of research method, the identification of ecological resources is the first step in the evaluation of ecological potential in the area; in order to prepare the land for assessment, the resources must be spotted. Therefore, it is attempted to identify the area's ecological resources, which in this section the necessary maps has been plotted and presented based on the studied area. The second step is the process of evaluation of analysis capacity and summary of the resources, 
which is considered as the combination of all classes with each other to obtain units or unit consists of homogeneous classes of ecological resources. Fig. 8 indicates results of summarized resources in the studied area. There are seven classes associated with the proposed study of this paper.

In class 1, land is capable of systematic cultivation of agricultural products, intensive gardening, livestock holding, a poultry and bee keeping. In terms of climate, it maintains hypothermal or temperate humid or temperate semi-moist or sub-Mediterranean. The region maintains an annual water content of up to $10^{6}$ thousand cubic meters per hectare and percentage slopes reaches up to 5 . In terms of soil texture, it maintains clay, clayloam, humus and in terms of soil structure the region contains small to medium without gravel and transformed. The region has deep soil depth and it is highly desirable in terms of soil fertility. In terms of soil drainage conditions, it maintains complete drainage and it has a negligible to very little erosion risk. Finally, in this region, soil does not have potential to become salty or hidromorph after long-term irrigation and has medium to high potential for permanent cultivation and irrigation without facing loss.

In class 2, land has the potential for the cultivation of agricultural products but not for continuous harvest. Also for farm, horticultural, husbandry, poultry and beekeeping has good power. In terms of climate, it is suitable for the cultivation of some agricultural products, but has some limitations (cold, dry). The region maintains 4 to 6 thousand cubic meters per hectare as annual water content and percent slopes goes up to 8. In terms of soil texture, it is loam clay, humus clay, sandy clay loam, sandy clay loam, clay loam and loamy. In terms of soil structure, the region maintains the same characteristics as class 1 . It maintains semi-deep to deep soil depth, maintains desirable soil fertility, the region maintains well soil drainage conditions, the erosion risk is low to medium.

In class 3, land for the cultivation of agricultural products is suitable but not for continuous harvest. The land has low to medium potency for farm land, horticulture, animal husbandry, poultry and beekeeping. In terms of climate, there are a number of local agricultural products for cultivation and in terms of annual water content, it maintains 3 to 5 thousand cubic meters per hectare with a percentage slop of up to 8 . In terms of soil texture, the region is clay loam, loam sandy, loam clay sandy, clay loam sandy, sandy and probably clay loam. In terms of soil structure, it is medium to coarse with grave land rubble probably, partially transformed. In terms of soil depth it has low to semi-deep region and in terms of soil fertility, the region is somehow desirable with soil drainage conditions of partial to medium.

In class 4, the land has a high potency for pasture land and homebred cultivation, planting fruit trees with irrigation and without irrigation, and has a low to medium potency for poultry husbandry and beekeeping. In terms of climate, many agricultural products are suitable for homebred farming and annual rainfall is over $400 \mathrm{~mm}$. The region maintains percent slopes from 8 to 15, soil texture characteristics include clay, clay loam, loam clay and loam. Soil structure is small to medium with gravel and semi-transformed to transformed with semi deep. In addition, the region maintains somehow desirable to desirable soil fertility with medium to well soil drainage conditions, erosion risk is medium. Finally, density of herbaceous cover is more than $70 \%$, the species composition of herbaceous coverage is more than cereals and introducing.

In class 5, the land has a medium potency for pasture land and homebred farming and for growing fruit. Trees with no irrigation and no irrigation, and has a low to medium potency for poultry husbandry and beekeeping. In terms of climate, many agricultural products are suitable for homebred farming and annual rainfall is over $400 \mathrm{~mm}$. Annual water content is this region contains up to three thousand cubic meters with percent slopes from 8 to 15, the soil texture is loam clay, clay loam, loam sandy, loam clay sandy, clay loam sandy, sandy and loam. In terms of soil structure, it is semi medium to coarse with gravel or rubble and semi-transformed to transformed. It has low to medium soil depth, low to somehow desirable soil fertility, soil drainage conditions are partial (dry soil) to medium and finally the region has medium to high level of erosion risk. In summary, density of 
herbaceous cover and the species composition of herbaceous coverage is the same as class 4 . The amount of hay per year is 350-500 kg per hectare, land due to poor soil conditions probably salinity or alkalinity of the soil and climate, has lower potential for pasture land and homebred cultivation than class 4.

In class 6, land for beekeeping and gardening terrace has a low potency. It has very little potential for pasture and it has no potency for other branches of agriculture especially the cultivation. In terms of climate, land is suitable for growth pasture plants and annual rain fall is less than $400 \mathrm{~mm}$ with percent slopes from 30 to 15 . Soil texture includes loam sandy, clay loam sandy, sandy and loamy. Soil structure is medium to coarse with gravel or rubble and rock and semi-transformed. Soil depth is low to semi-deep, soil fertility is imperfect to somehow desirable, soil drainage conditions is partial to medium and erosion risk medium to high. Density of herbaceous cover: more than 70 to 200/0- and the species composition of herbaceous coverage is the same as class 4 , the amount of hay per year is from 250 to $350 \mathrm{~kg}$ per hectare. In addition, land is suitable for poor pasture land or terracing gardening and beekeeping for local residents. The land is more suitable for grazing wild animals' habitant in the area.

Finally, in class 7, land is not suitable for pasture and agricultural. It has potency for grazing land for wildlife conservation. Land is not suitable for growth pasture plants (annual rainfall, very low annual temperatures or very high annual temperature). Percent slopes is more than 30 , soil structure is like a thin leaf on a rock and untransformed. Soil fertility is low and erosion risk is medium to high. The region has a probability of slip, the area is so full of trees, which does not allow to under floor plants to growth, density of herbaceous covers less than $20 \%$.

The second step is the process of evaluation of analysis capacity and summary of the resources, which is considered as the combination of all classes with each other to obtain units or unit consists of homogeneous classes of ecological resources. Fig. 8 indicates results of summarized resources in the studied area.

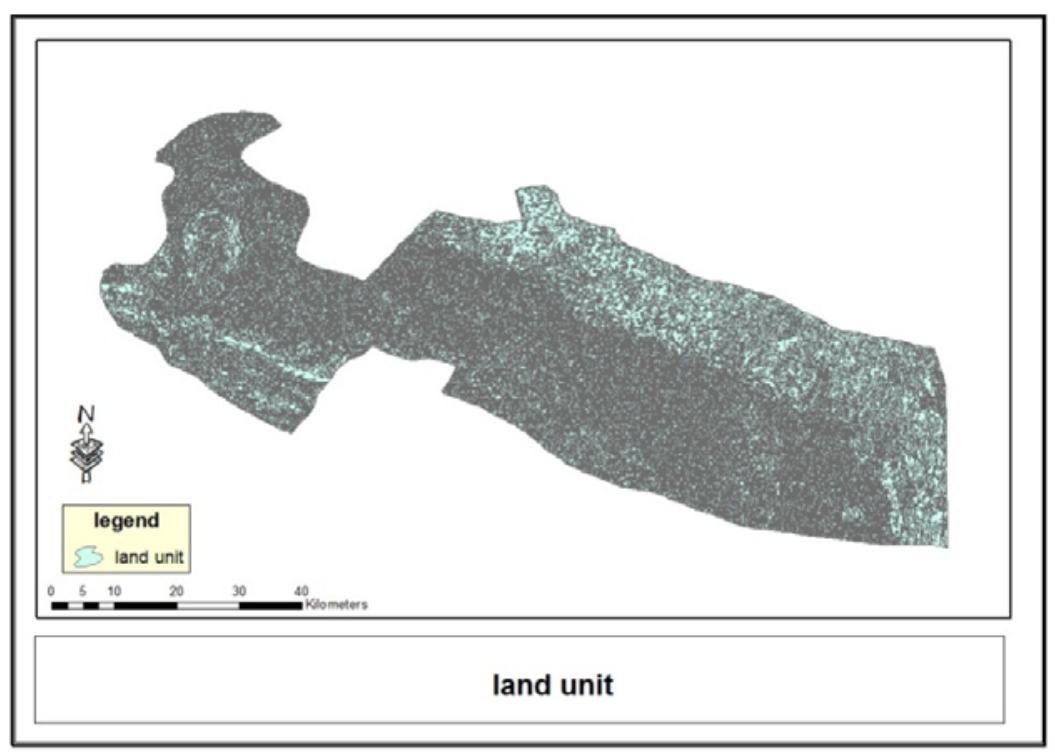

Fig. 8. Land unit

The third step involves the evaluation of agricultural ecological environment in determining capable areas. In this step, from the collected data in the analyzing and summarizing step in environmental unit along with ecological models, which is made for different application; the most appropriate 
activities are selected. Fig. 9 indicates capable agricultural areas in the location by using of presented model in the research method.

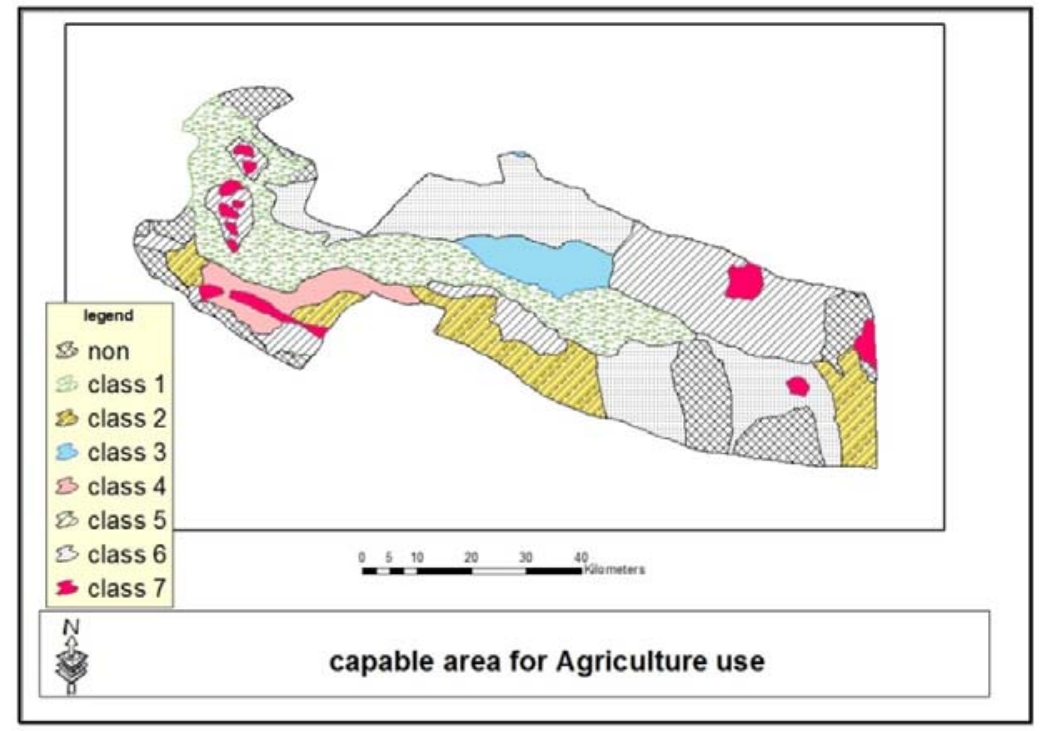

Fig. 9. Capable area for agriculture use

\section{Discussions and Conclusions}

As we can observe from Fig. 9, which is the result of the analysis of the whole study process, in the studied area based on the definition of ecological capability evaluation model, the land spread in the area with grades from 1 to 7 . An accurate survey on the results and its comparison with the area situation indicates that the conditions are provided for agriculture in these areas (for example, the studied area has desirable soil) and agriculture in the area should be strengthened. In the present situation, poor management of water resources has seriously threatened this capability. With regard to the high potential for agricultural activities in the area, the study has indicated important factors to be seriously considered. We have also presented possible suggestions to handle water resources management challenges. Note that there is an area, as a preservative line, which is located between Esfahan and central desert of Iran and encounters change use. This will act as opening the gates of Esfahan metropolitan into desert, and then desertification would be widespread. Therefore, it is necessary to consider certain essential measures before environmental crisis occurs, and appropriate solutions is executed for sustainable management of surface water resources which mainly supply from the Zayande Rood River and agriculture can be continued as the dominant activity in the area. In addition, the population stability in the studied area prevents from rural migration to city; a major step towards sustainable rural development is carried out in accordance with environmental features.

\section{References}

Agriculture Organization of Isfahan province (2012).

Alberta Urban Municipalities Association (2007). Sustainable land use planning, analysis and recommendation Adopted by the AUMA Convention.

Carsjens, G.J., \& van der Knaap, W. (2002). Strategic land-use allocation: dealing with spatial relationships and fragmentation of agriculture. Landscape and Urban Planning, 58(2-4), 171-179

Dasman, R.F. (1984). Environmental conservation $5^{\text {th }}$ ed., Wiley and Sons. New York, 486.

FAO (Food and Agriculture Organisation Of The united nations ( 1993). Guidelines for land-use planning, Rome, 74. 
Gulinck, H.,Vyverman, N., VanBouchout, K. \& Gobin, A. (2001). Landscape as framework for integrating local subsistence and ecotourism: a case study in Zimbabwe. Landscape and Urban Planning, 53, 173-182.

Isfahan tourism master plan (2009). Cultural heritage, Handcrafts and Tourism Organization of Isfahan Province.

Makhdoom, M. (1991). Ecological evaluation of Gilan province for development, Journal of Environmental Studies, 16, University of Tehran (In Persian).

Makhdoom, M. (2005) Fundamental of Land Use Planning, University of Tehran, 185-212.

Miller, G.T. (1994). Rural Resource Management: Problem Solving for the Long Term. Iowa State University Press; $1^{\text {st }}$ edition.

National Center of Land use planning of Iran. (2005). Guide for provincial planning programs studies. 14.

NorooziAvargani, A. (2002) The study of Environmental potential in the development, Master's Thesis, university of Isfahan, 23.

Quaye, A.K., Hall, C.A.S., \& Luzadis, V.A. (2010). Agricultural land use efficiency and food crop production in Ghana. Environment, Development and Sustainability, 12(6), 967-983

Santelmann, M.V. et al. (2004). Assessing alternative futures for agriculture in Iowa, U.S.A. Landscape Ecology, 19(4), 357-374.

Smith, W., \& Kelly, S. (2003). Science, Technical expertise and the human environment , School of Geography and Environmental Science, The University of Auckland, New Zealand, 324.

Scottish Environment LINK (2009). Living with the Land Proposals for Scotland's First Sustainable Land Use Strategy, www.scotlink.org, pp3.

Tavakol, M. S. (1998). Necessary environmental evaluation of physical and development plans. Journal of Environmental Studies, 18, University of Tehran.

The World Bank. (2006). Sustainable Land Management, challenges, opportunities, and tradeoffs, http://www.worldbank.org. 